\title{
AC 2008-172: VISUAL BASIC SOFTWARE FOR DESIGN AND PERFORMANCE PROBLEMS
}

\section{Noah Brak, West Virginia University}

Noah Brak is an undergraduate student studying chemical engineering at West Virginia

University.

\section{Joseph Shaeiwitz, West Virginia University}

Joseph A. Shaeiwitz received his B.S. degree from the University of Delaware and his M.S. and Ph.D. degrees from Carnegie Mellon University. His professional interests are in design, design education, and outcomes assessment. Joe is an associate editor of the Journal of Engineering Education, and he is a co-author of the text Analysis, Synthesis, and Design of Chemical Processes (2nd ed.), published by Prentice Hall in 2003.

\section{Richard Turton, West Virginia University}

Richard Turton received his B.S. degree from the University of Nottingham and his M.S. and $\mathrm{Ph} . \mathrm{D}$. degrees from Oregon State University. His research interests are include fluidization and particle technology and their application to particle coating for pharmaceutical applications. Dick is a co-author of the text Analysis, Synthesis, and Design of Chemical Processes (2nd ed.), published by Prentice Hall in 2003. 


\section{Visual Basic Software for Design and Performance Problems}

\section{Introduction}

Most chemical engineering textbooks still show graphical solutions for certain routine design calculations. The Moody plot for friction factors, which is based on experimental data, and the corresponding plots for flow past submerged objects are examples. However, in recent years, curve fits for these have yielded equations that are at least as accurate as reading a graph. Graphs of the Kremser and Colburn equations for separations in dilute systems are another example; although, these equations were derived in order to construct the plots. For heat exchangers, the log-mean-temperature-difference (LMTD) correction factor is generally read from a graph since most textbooks do not provide the appropriate equations, even though the graphs are obtained from these equations.

If the equations are used, it is possible to obtain the information found on the graph and to do design and performance calculations more accurately by means of a computer program. In this paper, we describe Visual Basic for Applications (VBA) programs written for the following design problems: flow in pipes, flow past submerged objects (including packed and fluidized beds), separation in dilute systems, and heat exchangers. The programs not only find the parameters usually obtained from a graph (friction factor, drag coefficient, absorption or stripping factor, LMTD correction factor) but they also perform routine design and performance calculations. The definitions used here are that a design calculation is used to determine the size of a unit with a given input and a desired output, and a performance calculation is used to determine the output of a unit with a given input and a given size.

These programs are not meant to replace process simulators; they are meant to be teaching tools that are more accessible to students than process simulators.

\section{Description of Programs}

Table 1 summarizes the programs that will be available for demonstration. Additional details of each program follow.

\section{$\underline{\text { Separation in Dilute Systems }}$}

The relationships used are the Kremser equation ${ }^{1}$

$$
\frac{y_{A, \text { out }}-y_{A, \text { out }}^{*}}{y_{A, \text { in }}-y_{A, \text { out }}^{*}}=\frac{1-A}{1-A^{N+1}}
$$

if $A=1$

$$
\frac{y_{A, \text { out }}-y_{A, \text { out }}^{*}}{y_{A, \text { in }}-y_{A, \text { out }}^{*}}=\frac{1}{N+1}
$$









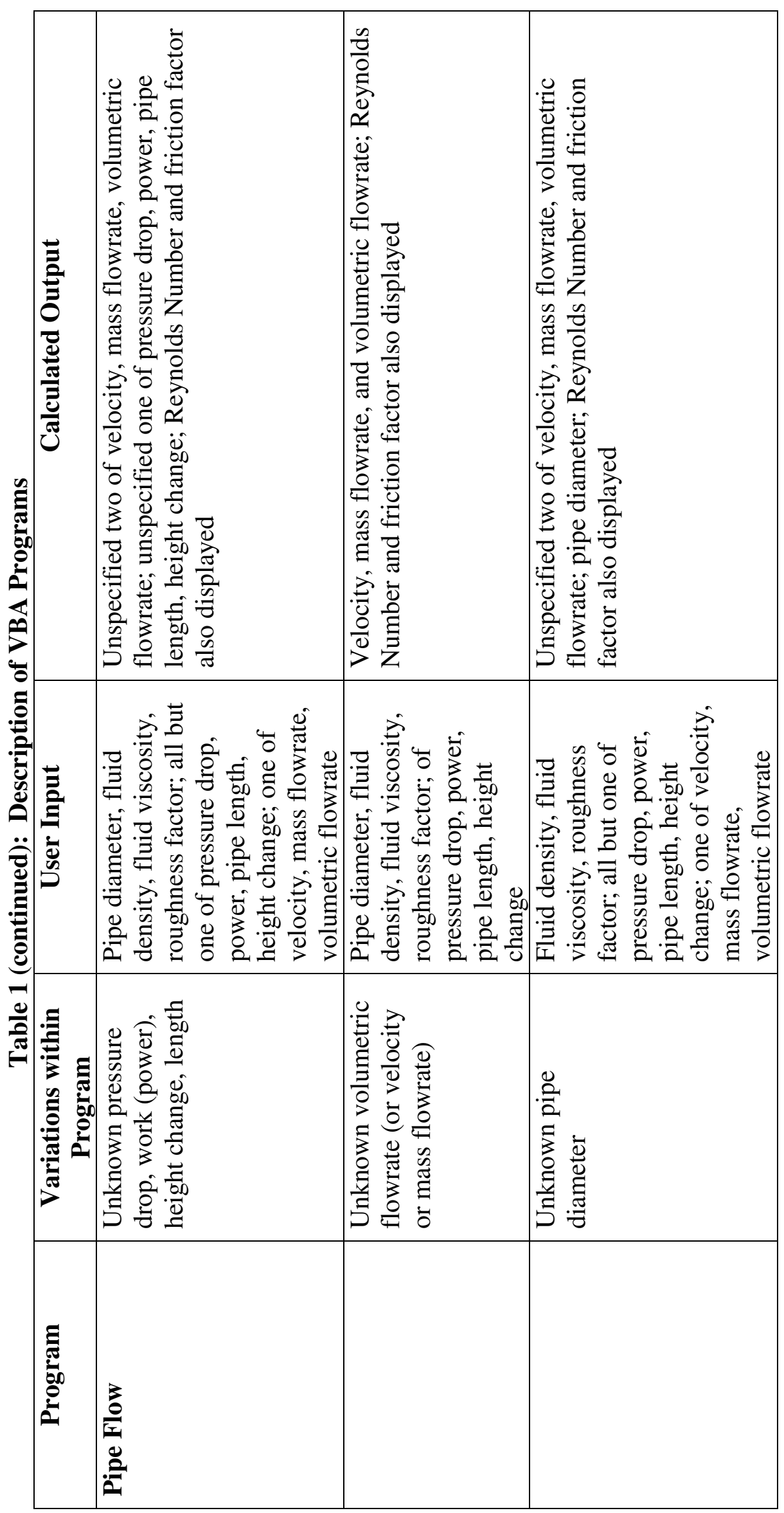

D
$\stackrel{D}{0}$
$\mathbb{D}$
$\vec{\omega}$
$\vec{\omega}$
$\dot{\infty}$
$\infty$
$+\infty$ 


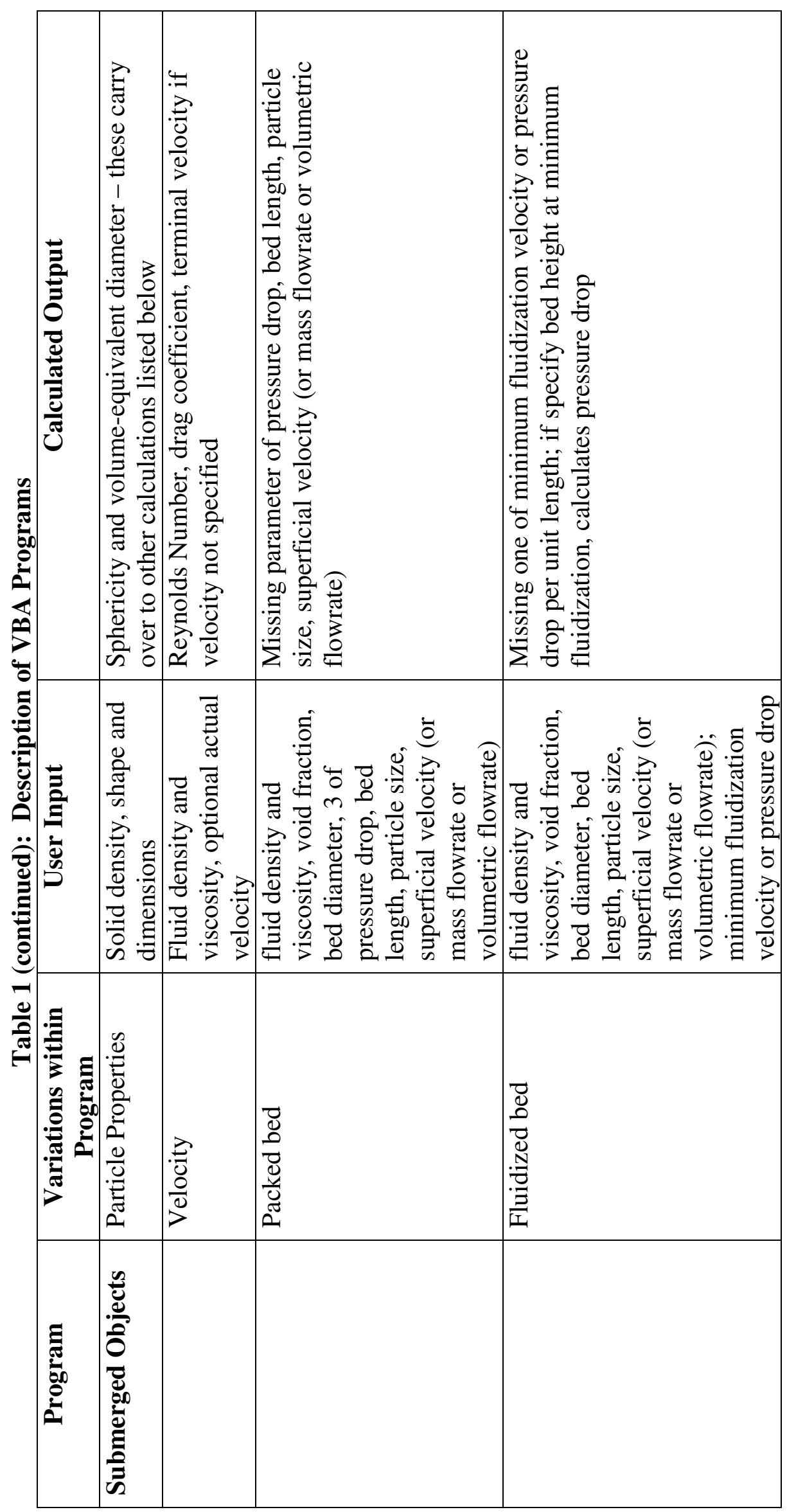

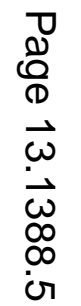


and the Colburn equation ${ }^{1}$

$$
\frac{y_{A, \text { out }}-y_{A, \text { out }}^{*}}{y_{A, \text { in }}-y_{A, \text { out }}^{*}}=\frac{1-\frac{1}{A}}{\exp \left[N_{t o G}\left(1-\frac{1}{A}\right)\right]-\frac{1}{A}}
$$

if $A=1$

$$
\frac{y_{A, \text { out }}-y_{A, \text { out }}^{*}}{y_{A, \text { in }}-y_{A, \text { out }}^{*}}=\frac{1}{N_{\text {toG }}+1}
$$

These equations are written for absorption, and there are equivalent equations for stripping.

There are three parameters, the absorption (stripping) factor, $A$, the number of equilibrium stages (or number of transfer units), $N\left(N_{t o G}\right)$, and a dimensionless concentration group in which the outlet mole fraction of the feed stream is usually the unknown. In this dimensionless concentration group, $y^{*}$ A.out $=m x_{A, \text { in }}$. The graph is usually drawn with the dimensionless mole fraction as the ordinate and the number of stages (transfer units) as the abscissa, with the absorption (stripping) factor as curves. The program allows one parameter to be calculated if the other two are specified, either for absorption or for stripping or for staged or continuous differential separations. The absorption factor is defined as $L / m G$, where $L$ and $G$ are the liquid and gas molar flowates, and $m$ is the distribution coefficient. If Raoult's Law is assumed, $m=$ $p^{*} / P$, where the numerator is the vapor pressure, which is a function of only temperature, and the denominator is the total pressure. For this case, if any three of temperature, total pressure, liquid flowrate, or vapor flowrate are specified, the program calculates the missing parameter. Either the Antoine's constants may be entered or a pull-down menu may be used to select a component. If Henry's Law is assumed, $m$ (which must be assumed constant) and one molar flowrate must be entered, and the missing molar flowrate is calculated. An experimental partition coefficient can be entered in place of a Henry's Law constant.

\section{$\underline{\text { Heat Exchangers }}$}

For the design problem, the energy balances for each stream (no phase change for either stream) and the design equation are solved. In the energy balance, there are four temperatures, two heat capacities, and two mass flowrates. The program solves for the eighth parameter if any seven are specified. The program also solves for the LMTD correction factor for a variety of heat exchanger configurations. For example, the equations for a 1-2 heat exchanger are ${ }^{2}$ 


$$
F=\frac{\sqrt{R^{2}+1} \ln \left[\frac{1-P}{1-R P}\right]}{(R-1) \ln \left[\frac{2-P\left(R+1-\sqrt{R^{2}+1}\right)}{2-P\left(R+1+\sqrt{R^{2}+1}\right)}\right]}
$$

and for $R=1$

$$
F=\frac{P \sqrt{2}}{(1-P) \ln \left[\frac{2-2 P+P \sqrt{2}}{2-2 P-P \sqrt{2}}\right]}
$$

where

$$
\begin{gathered}
P=\frac{t_{\text {out }}-t_{\text {in }}}{T_{\text {in }}-t_{\text {in }}} \\
R=\frac{\operatorname{n\& }_{\text {tube }} C_{p, \text { tube }}}{n \&_{\text {hell }} C_{p, \text { shell }}}=\frac{T_{\text {in }}-T_{\text {out }}}{t_{\text {out }}-t_{\text {in }}}
\end{gathered}
$$

where $n$ \&is the mass flowrate of the stream, $C_{p}$ is the heat capacity of the stream, $t$ is the temperature in the tube, and $T$ is the temperature in the shell.

If the overall heat transfer coefficient is specified, the area is also calculated. As an alternative, the temperature parameters, usually denoted $R$ and $P$, may be the input; in this case the energy balance is ignored and only the LMTD correction factor is calculated. There is no allowance for phase changes, since the LMTD correction factor is one for these cases (for a pure component).

For the performance problem, the flowrates, heat capacities, inlet temperatures, area, and overall heat transfer coefficient are the inputs. The program calculates the outlet temperatures for a specified heat exchanger configuration. (See the screen shot in Figure 5 in the appendix for the different configurations included.)

Screen shots for an example problem are shown in the appendix.

\section{Pipe Flow}

For pipe flow, the mechanical energy balance (MEB) and a curve fit for the friction factor $(f)$ are solved simultaneously. The chosen curve fit is the Pavlov equation ${ }^{3}$ 


$$
\frac{1}{\sqrt{f}}=-4 \log _{10}\left[\frac{\varepsilon}{3.7 D}+\left(\frac{6.81}{\operatorname{Re}}\right)^{0.9}\right]
$$

where $\varepsilon$ is the roughness factor of the pipe, $D$ is the pipe diameter, $R e$ is the Reynolds number

If one of the pressure drop, pipe length, height change, or power is unknown, the unknown is calculated if the other three are specified. The pipe diameter, pipe roughness, flowrate (mass or volumetric) or velocity, and fluid properties must also be specified. Data for typical schedule pipe sizes and for some fluid densities are included in pull-down menus. This is the typical sequential calculation where the friction factor is first calculated followed by using the MEB to find the only unknown. The program also tests for laminar or turbulent flow, so solutions in the transition region may not be accurate.

If the flowrate (velocity) is unknown, the MEB and the friction factor equations are solved simultaneously for the flowrate (velocity). All parameters other than the flowrate (velocity) must be specified.

If the diameter is unknown, the MEB and friction factor equations are solved simultaneously for the diameter. The standard schedule pipe that corresponds to the solution must be determined by the user.

Screen shots for an example problem are shown in the appendix.

$\underline{\text { Submerged Objects, Packed Beds, and Fluidized Beds }}$

This program mimics the pipe flow program for flow past submerged objects. Solid properties and dimensions can be provided, and the program will calculate the sphericity and the volume equivalent diameter. These results carry over to other parts of the program.

The terminal velocity for an object may be calculated by providing the fluid properties. Alternatively, the actual velocity may be provided, and the program calculates the drag coefficient and the Reynolds number. The drag coefficient is obtained from the equation of Haider and Levenspiel ${ }^{4}$

$$
C_{D}=\frac{24}{\operatorname{Re}_{p}}\left[1+\left(8.171 e^{-4.0655 \psi_{w}}\right) \operatorname{Re}_{p}^{\left(0.0964+0.5565 \psi_{w}\right)}\right]+\frac{73.69 \operatorname{Re}_{p} e^{-5.0748 \psi_{w}}}{\operatorname{Re}_{p}+5.378 e^{6.2122 \psi_{w}}}
$$

where $\psi_{w}$ is the sphericity of the particle, and the Reynolds number, $\operatorname{Re}_{p}$ is defined as

$$
\operatorname{Re}_{p}=\frac{D_{p} v \rho}{\mu}
$$


where $v$ is the "slip" velocity, $\mu$ is the fluid viscosity, $\rho$ is the fluid density, and $D_{p}$ is the diameter of a sphere with the same volume as the particle.

For packed beds, the program uses the general form of the Ergun equation, and the parameters are bed length (height), particle size, bed diameter, superficial velocity, and pressure drop. The program calculates any one of these if all others are specified.

For fluidized beds, the parameters are minimum fluidization velocity and pressure drop per unit length. If one is specified, the other is calculated. Additionally, if the bed height at minimum fluidization is specified, the pressure drop is calculated.

\section{Discussion}

These programs are designed to allow students to perform many calculations rapidly. They are not intended to replace the understanding that arises from studying the graphs found in textbooks. The graphs illustrate many important concepts, such as the inability to achieve certain separations of the absorption factor is less than one, the rapid decrease in LMTD correction factor as the parameter $P$ increases, or the friction factor approaching a constant value at high Reynolds numbers. These programs are intended to permit repeated, rapid, calculations with more accuracy than reading a graph. They are also intended to free the student from writing code or using the Excel solver, though there may be beneficial learning from that exercise.

We have not yet used these programs in classes because of the timing of their development. They will be made available next year in the unit operations classes and in the capstone design class.

\section{Conclusion}

Visual Basic for Applications (VBA) programs, running in Microsoft Excel ${ }^{\circledR}$, for design and performance problems for separation in dilute systems, heat exchangers, pipe flow, and flow past submerged objects have been developed. These are meant to replace the use of graphs such as those for the Moody plot and LMTD correction factor for routine design and performance calculations in a teaching/learning environment.

Bibliography

1. Turton, R., R. C. Bailie, W. B. Whiting, and J. A. Shaeiwitz, Analysis, Synthesis, and Design of Chemical Processes (2 ${ }^{\text {nd }}$ ed.), Prentice Hall, Upper Saddle River, NJ, 2003, pp. 572-573.

2. Bowman, R. A., A. C. Mueller, and W. M. Nagle, "Mean Temperature Difference in Design," Transactions of the ASME, 62, 283-294 (1940).

3. Levenspiel, O. Engineering Flow and Heat Exchange (revised ed.), Plenum Press, New York, 1998, p. 26.

4. Haider, A. and O. Levenspiel, "Drag Coefficient and Terminal Velocity of Spherical and non-Spherical Particles,” Powder Technology, 58, 63 (1969). 


\section{Appendix - Examples with Screen Shots Illustrating VBA Programs}

\section{Example 1}

Hot water at $43^{\circ} \mathrm{C}$ flows from an open, constant-level tank through 2 in schedule 40 steel pipe, from which is emerges to the atmosphere $12.2 \mathrm{~m}$ below the level in the tank. The equivalent length of the piping system is $45.1 \mathrm{~m}$. Calculate the flowrate.

This problem requires simultaneous solution of a friction factor equation and the mechanical energy balance, with the velocity as the unknown. Karman plots $\left(f\right.$ vs. $\left.\operatorname{Re} \times f^{0.5}\right)$ have also been used to solve this type of problem (Bennett, C. O., and J. E. Myers, Momentum, Heat, and Mass Transfer ( $3^{\text {rd }}$ ed.), New York, McGraw Hill, 1982, p. 205.). The program solves the two equations simultaneously and provides the velocity, mass flowrate, volumetric flowrate, friction factor, and Reynolds number. 


\section{Input screen:}

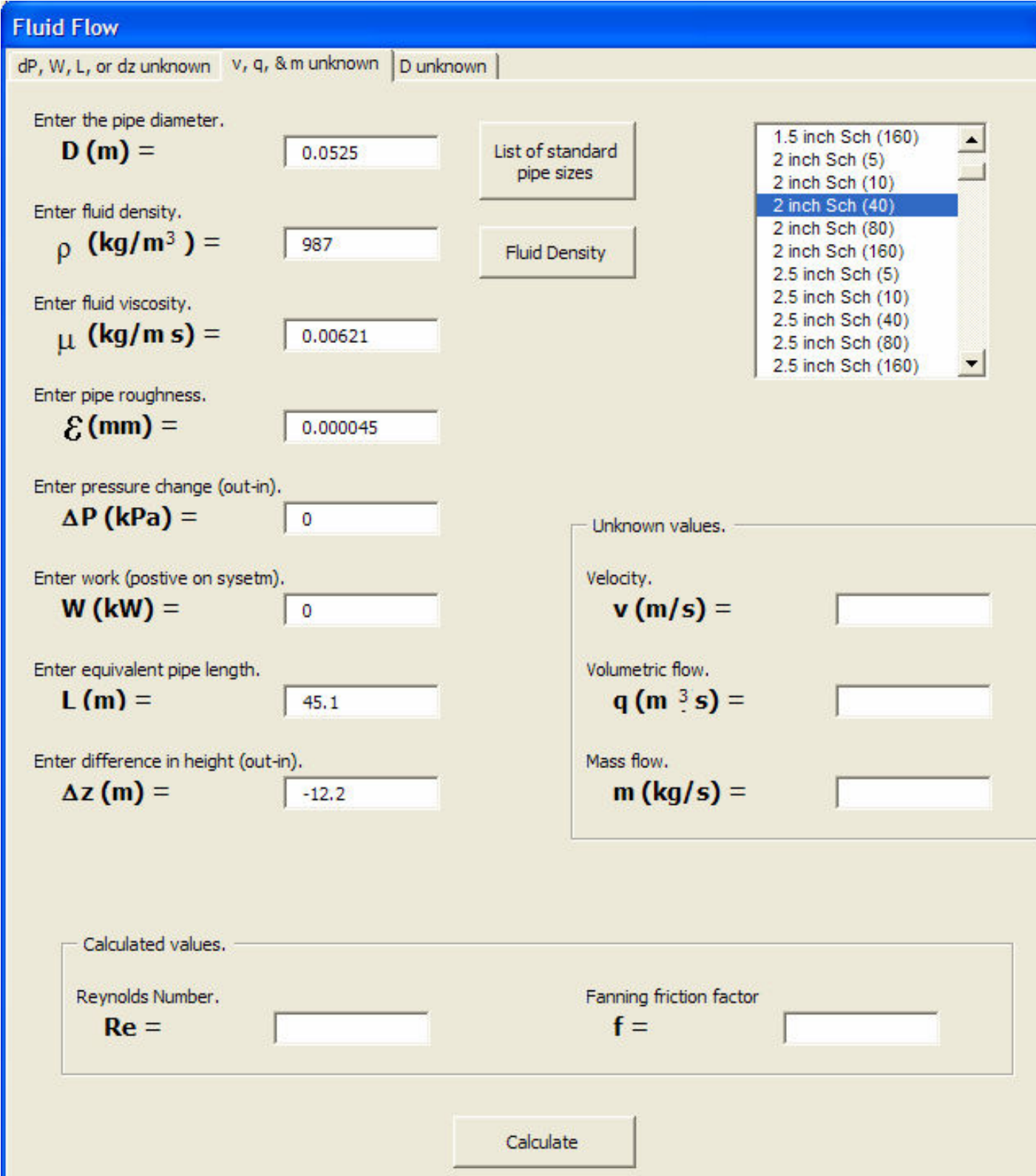




\section{Result screen}

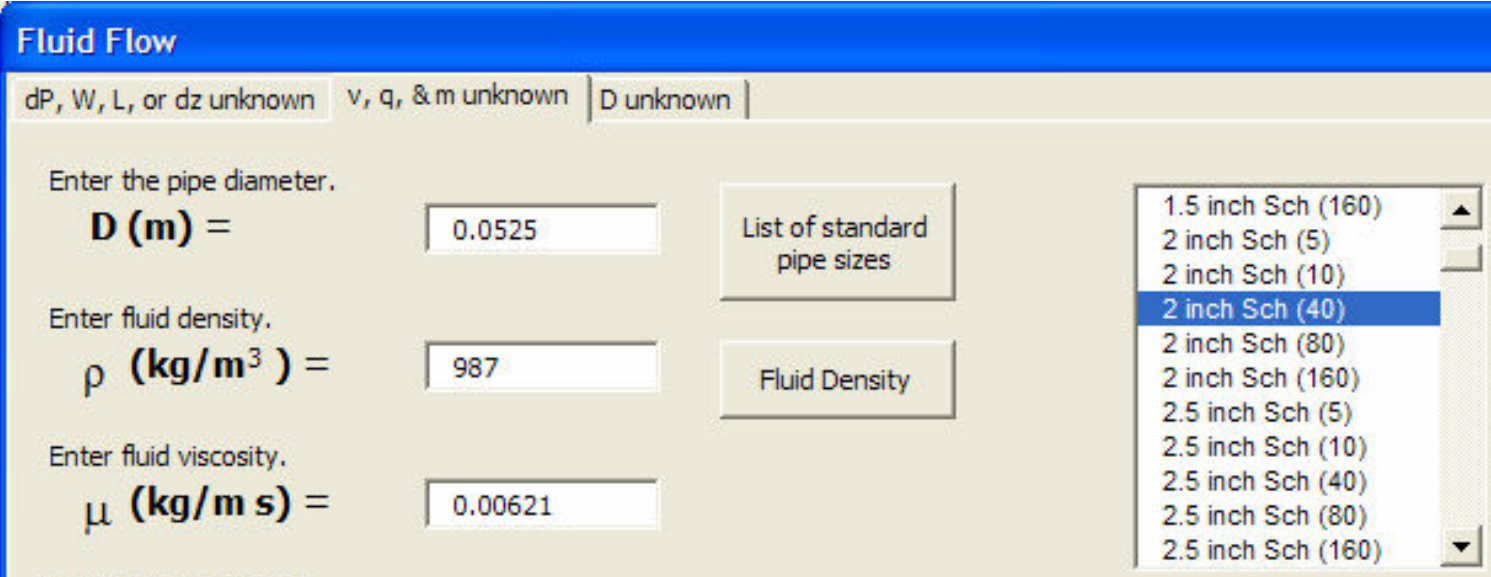

Enter pipe roughness.

$$
\mathcal{E}(\mathrm{mm})=\quad 0.000045
$$

Enter pressure change (out-in).
$\Delta \mathbf{P}(\mathbf{k P a})=$
0

Enter work (postive on sysetm).

$\mathbf{W}(\mathbf{k W})=\quad 0$

0

Enter equivalent pipe length.
$\mathbf{L}(\mathbf{m})=$
45.1

Enter difference in height (out-in).
$\Delta \mathrm{z}(\mathrm{m})=$
$-12.2$

Unknown values,

Velocity.

$\mathbf{v}(\mathrm{m} / \mathrm{s})=$

3.338

Volumetric flow.

$$
\mathbf{q}\left(\mathrm{m}^{3} \mathrm{~s}\right)=
$$

0.007

Mass flow.

$$
\mathrm{m}(\mathrm{kg} / \mathrm{s})=
$$

7.133

Calculated values.

Reynolds Number.

$\mathrm{Re}=$

27855.064

Fanning friction factor

$\mathbf{f}=$

0.00625

Calculate 


\section{Example 2}

Oil ( $\left.C_{p}=0.5 \mathrm{BTU} / \mathrm{lb}{ }^{\circ} \mathrm{F}, 4000 \mathrm{lb} / \mathrm{hr}\right)$ is to be cooled from $200^{\circ} \mathrm{F}$ to $160^{\circ} \mathrm{F}$ using water $\left(1.0 \mathrm{BTU} / \mathrm{lb}{ }^{\circ} \mathrm{F}, 1600 \mathrm{lb} / \mathrm{hr}\right)$ entering at $50^{\circ} \mathrm{F}$. The overall heat transfer coefficient, $U=45$ BTU/hrft ${ }^{2} \mathrm{~F}$.

a. What is the heat load on the exchanger?

b. What is the outlet water temperature?

c. What area is required for co-current flow?

d. What area is required for pure countercurrent flow?

e. What areas are required for a 1-2, 2-4, and a crossflow (shell mixed, tube unmixed) configurations?

f. A 1-2 heat exchanger has been constructed for this design with an area of $17.5 \mathrm{ft}^{2}$. Now, suppose that the oil flowrate is increased to $4400 \mathrm{lb} / \mathrm{hr}$. If it is assumed that the heat transfer coefficient remains constant, what are the new outlet temperatures?

The first five parts are solved using the design mode. Part $\mathrm{f}$ is solved using the performance mode. Even though this problem is in American Engineering units, as long as the data are input in a consistent set of units, the correct solution is obtained. Therefore, the SI units are shown just for guidance. 


\section{Input Screen}
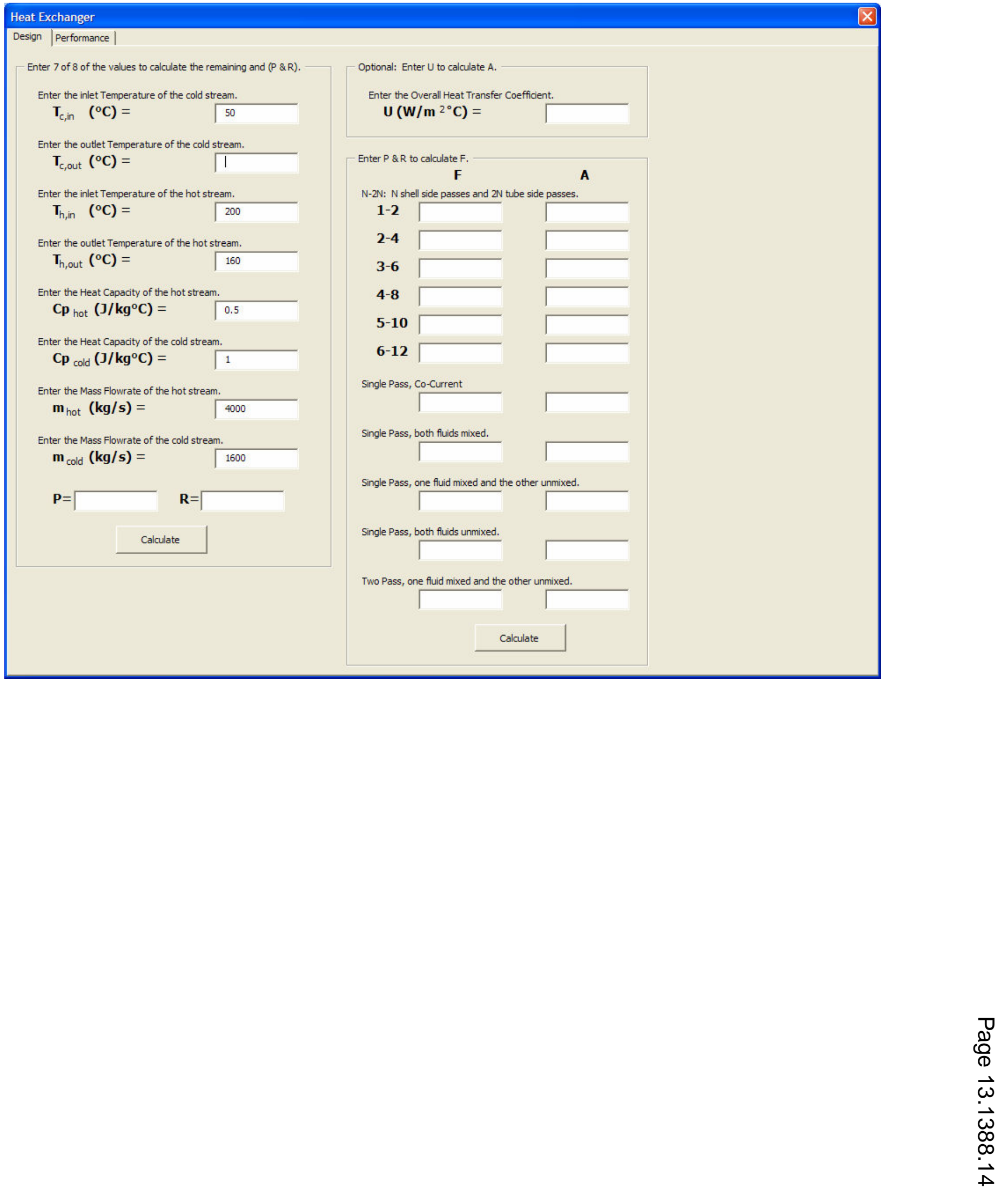


\section{Output Screen for Energy Balance}

\section{Heat Exchange}

Enter 7 of 8 of the values to calculate the remaining and $(P \& R)$.

Enter the inlet Temperature of the cold stream.

$\mathbf{T}_{\mathrm{c}, \text { in }}\left({ }^{\circ} \mathrm{C}\right)=\quad 50$

Enter the outlet Temperature of the cold stream.

$\mathbf{T}_{\mathrm{c}, \text { out }}\left({ }^{\circ} \mathrm{C}\right)=$

100

Enter the inlet Temperature of the hot stream.

$\mathbf{T}_{\mathrm{h}, \text { in }}\left({ }^{\circ} \mathbf{C}\right)=200$

Enter the outlet Temperature of the hot stream.

$\mathbf{T}_{\text {h,out }}\left({ }^{\circ} \mathrm{C}\right)=$

$$
160
$$

Enter the Heat Capacity of the hot stream $\mathrm{Cp}_{\text {hot }}\left(\mathrm{J} / \mathbf{k g}^{\circ} \mathrm{C}\right)=0$.

Enter the Heat Capacity of the cold stream.

$$
\mathrm{Cp}_{\text {cold }}\left(\mathrm{J} / \mathbf{k g}^{\circ} \mathrm{C}\right)=
$$

Enter the Mass Flowrate of the hot stream.

$\mathbf{m}_{\text {hot }}(\mathbf{k g} / \mathbf{s})=4000$

Enter the Mass Flowrate of the cold stream.

$$
\mathbf{m}_{\text {cold }}(\mathbf{k g} / \mathbf{s})=\quad 1600
$$

$$
\mathbf{P}=\longdiv { 0 . 3 3 3 } \quad \mathbf { R } = \longdiv { 0 . 8 }
$$

Optional: Enter U to calculate $\mathrm{A}$.

Enter the Overall Heat Transfer Coefficient. $\mathbf{U}\left(\mathbf{W} / \mathbf{m}^{2{ }^{\circ} \mathrm{C}}\right)=$

Enter $P$ \& R to calculate $F$

F

A

$\mathrm{N}-2 \mathrm{~N}$ : $\mathrm{N}$ shell side passes and $2 \mathrm{~N}$ tube side passes.

1-2

2-4

3-6

4-8

5-10

6-12
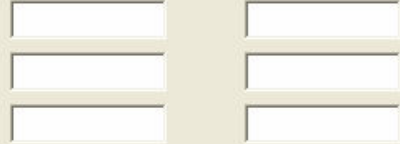

$-8$
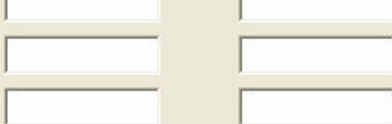

gle Pass, Co-Current

Single Pass, Co-Cin

Single Pass, both fluids mixed.

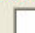

Single Pass, one fluid mixed and the other unmixed.

Single Pass, both fluids unmixed.

Two Pass, one fluid mixed and the other unmixed. 


\section{Output Screen for Heat Exchanger Design}

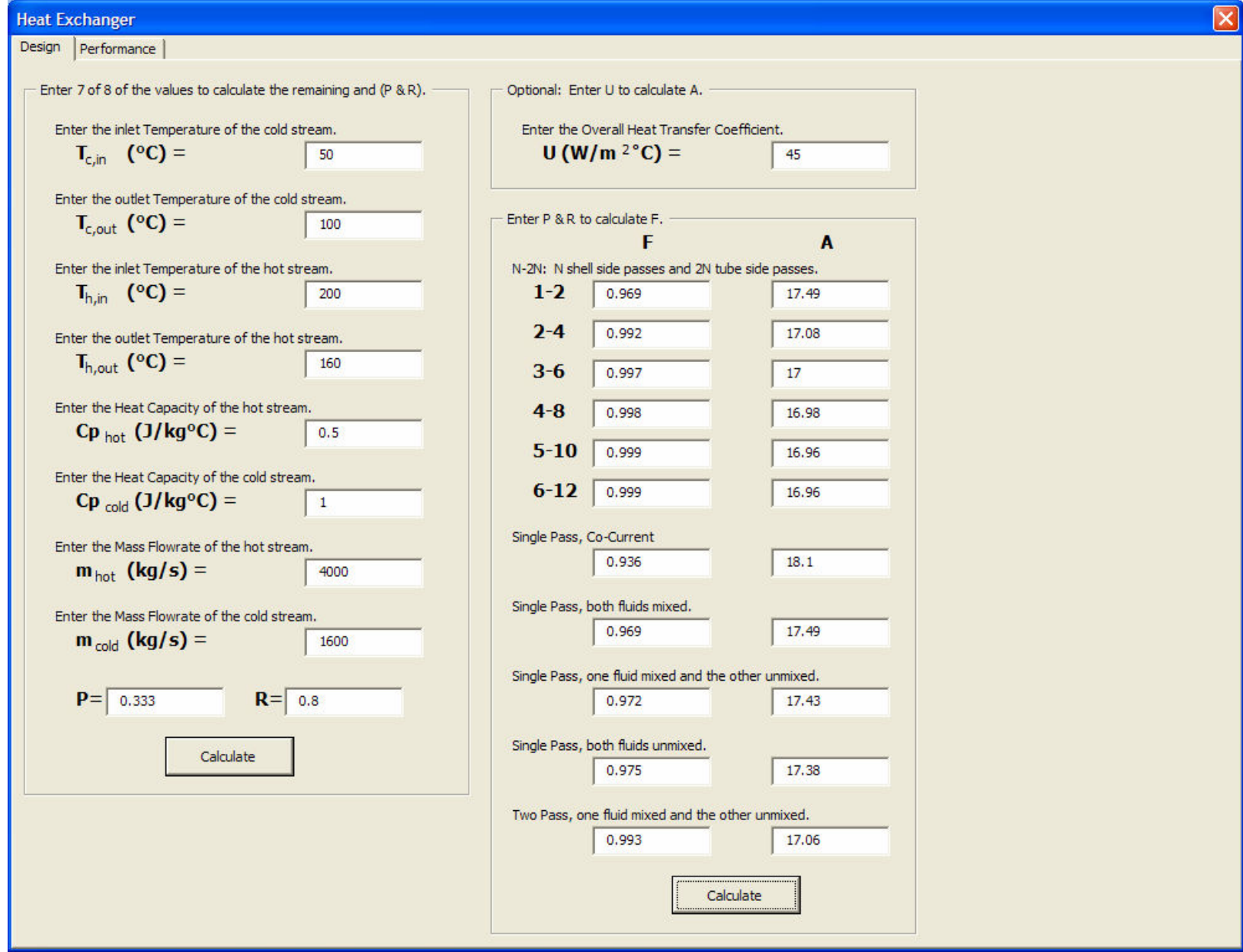

The program automatically calculates the LMTD correction factor and area for all configurations. 


\section{Input Screen for Part f, A Performance Calculation}

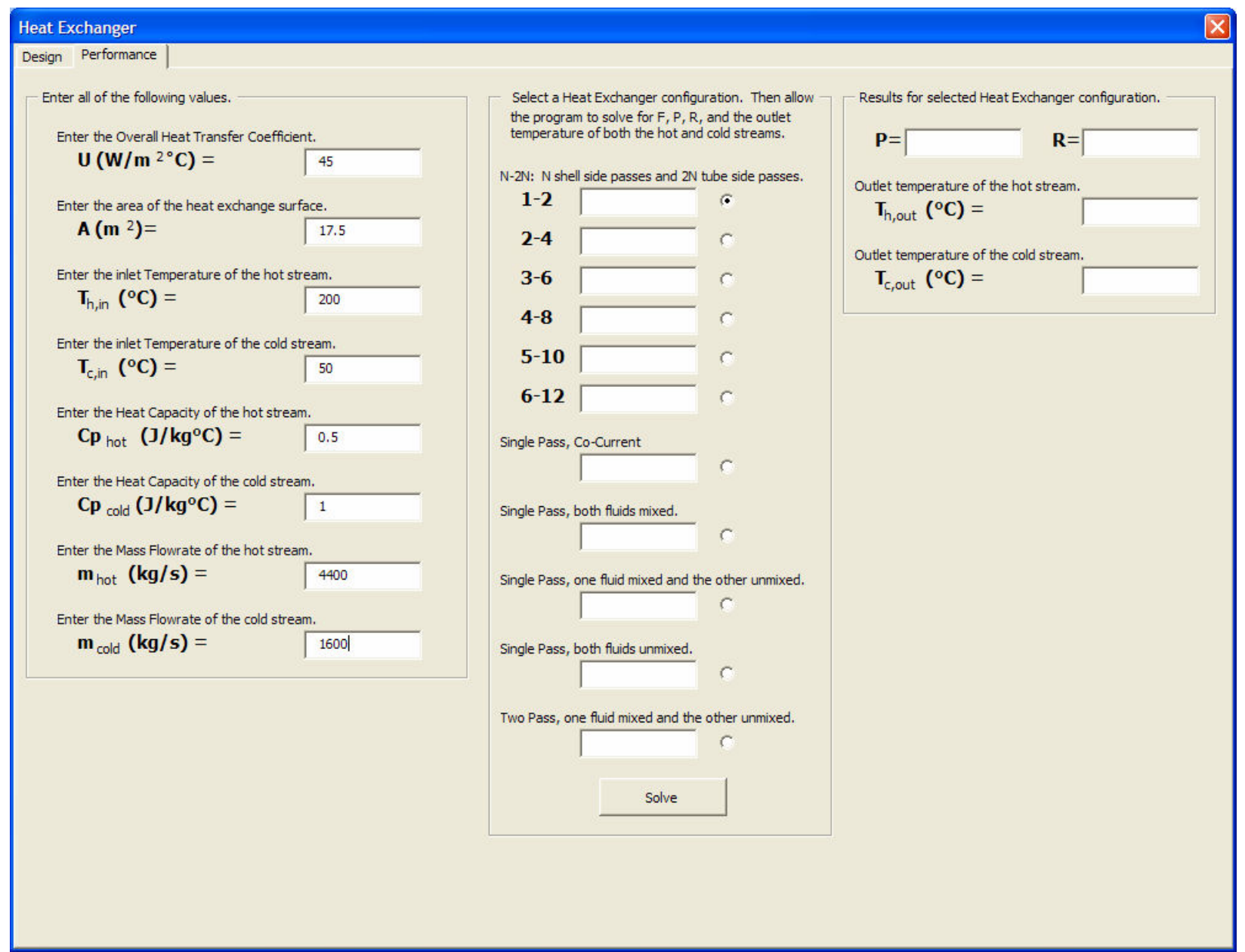

The performance problem is only solved for a chosen configuration. Here, the radio button for a 1-2 heat exchanger is checked. 


\section{Output Screen for Performance Problem}

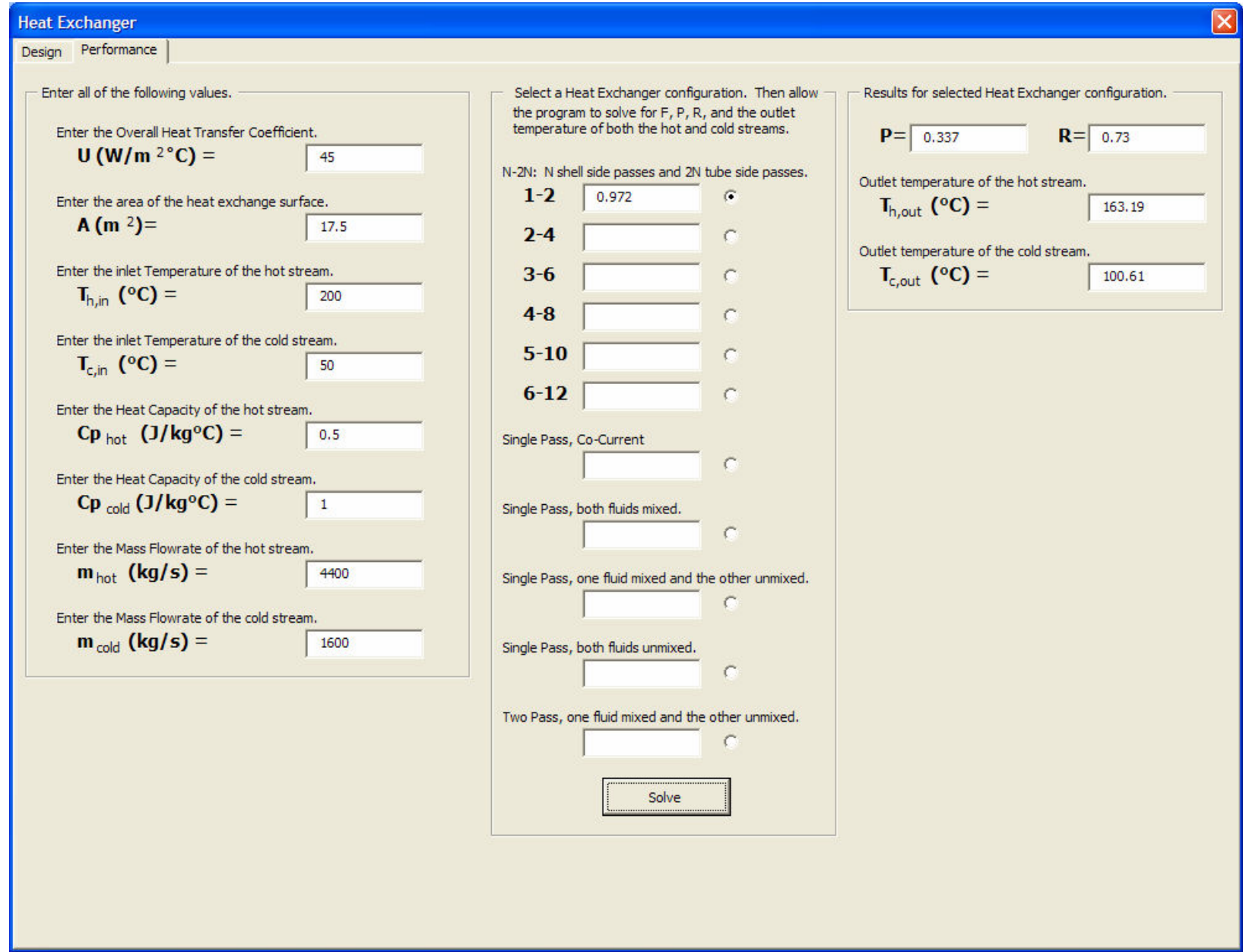

